\title{
A SÍNDROME DE BURNOUT NA ADMINISTRAÇÃO PÚBLICA MUNICIPAL: UM ESTUDO NA SECRETARIA MUNICIPAL DE ASSISTÊNCIA SOCIAL DE ITAOCARA/RJ
}

\section{ARTIGO ORIGINAL}

ERNANDES, Arianna Souza Sanches ${ }^{1}$

CÂNDIDO, Daniele de Paula ${ }^{2}$

SILVA, Mariana Borges ${ }^{3}$

ERNANDES, Arianna Souza Sanches. CÂNDIDO, Daniele de Paula. SILVA, Mariana Borges. A Síndrome de Burnout na Administração Pública Municipal: Um estudo na Secretaria Municipal de Assistência Social de Itaocara/RJ. Revista Científica Multidisciplinar Núcleo do Conhecimento. Ano 05, Ed. 06, Vol. 10, pp. 57-72. Junho de 2020. ISSN: 2448-0959, Link de acesso:

\section{RESUMO}

A Síndrome de Burnout é uma forma de resposta ao estresse ocasionando pela exaustão emocional do profissional e em razão da perda de sentido nas atividades relacionadas ao trabalho. O presente artigo busca evidenciar o contexto laboral do servidor público atuante na área de assistência social, buscando compreender as atividades exercidas e os fatores que podem ocasionar o desenvolvimento da doença, visto que o trabalho desempenhado na esfera da assistência social lida diretamente com a vulnerabilidade das pessoas. Trata-se de um levantamento bibliográfico de artigos e livros que foram consultados para conhecimentos gerais à respeito do assunto e, também, foi feita uma coleta de dados sobre o município.

\footnotetext{
${ }^{1}$ Graduanda em Administração Pública.

2 Graduanda em Administração Pública.

${ }^{3}$ Graduanda em Administração Pública.
} 
Palavras-chaves: Administração Pública, Burnout, assistência social, labor, psicologia organizacional.

\section{INTRODUÇÃO}

O labor é uma atividade de extrema importância na vida do ser humano. Além de ser fonte de sustento do indivíduo, é o local no qual o homem sente-se útil, produtivo e valorizado, aumentando sua autoestima, uma vez que passa a contar com uma maior possibilidade de autorrealização. No entanto, é preciso levar em conta que quando o trabalho é desenvolvido sob condições volúveis ou que expõem os servidores à grandes desgastes psicológicos pode tornar-se prejudicial à saúde, provocando doenças e ocasionando a inatividade. Nesses contextos instáveis e, muitas vezes, estressantes, surge a Síndrome de Burnout, equiparada a uma doença psicossomática, a qual tem se caracterizado como preocupante e notória na sociedade laboral atual, fato confirmado pelo aumento do número de pessoas que precisam ser afastadas do ambiente de trabalho por este motivo.

Assim sendo, cabe auferir que a Síndrome de Burnout é uma comorbidade representada por um esgotamento físico e mental ligado à execução de multitarefas e à uma sobrecarga na jornada laboral. $\mathrm{O}$ assunto tem sido estudado em outros países sob a denominação de Síndrome de Burned Out ou Burnout, e, no Brasil, recebe a denominação de Síndrome do Esgotamento Profissional. O termo Burnout tem sido utilizado quando o motivo primário do esgotamento está correlacionado com a atividade/ambiente profissional. Burnout é considerada uma síndrome que exaura o lado emocional do profissional, o que o leva a tomar atitudes cínicas e negativas com relação aos colegas de trabalho e a outros indivíduos para os quais se dirige sua prática. Isso ocorre porque seus recursos emocionais chegam ao limite do esgotamento.

Nesse sentido, torna-se válido destacar que a principal característica da síndrome é o estado de tensão emocional e estresse crônicos provocados por condições de trabalho físicas, emocionais e psicológicas intensas e que, portanto, desgastam o sujeito. O desgaste toma forma, sobretudo, em profissionais que, em sua prática, 
envolvem-se de forma direta e intensa com outros indivíduos. Dentre os setores da gestão pública municipal, a Assistência Social tornou-se o alvo do estudo pelo fato dos servidores apresentarem maior propensão a desenvolver esta síndrome, devido o contato direto com diversas situações de vulnerabilidade vividas por seus usuários. Dessa forma, o presente estudo apresentará uma análise da perspectiva laboral dos servidos públicos municipais que atuam no setor da Assistência Social do município de Itaocara, localizado no interior do Estado do Rio de Janeiro.

Dentre essas perspectivas, analisar-se-á os impactos emocionais, psicológicos e organizacionais oriundos das questões de conflitos vivenciadas nesse ambiente de trabalho.

\section{REFERENCIAL TEÓRICO}

As transformações ocorridas no contexto laboral, com o passar dos anos, são parâmetros que precisam ser discutidos, visto que são evidenciados no contexto histórico ao qual o desenvolvimento dos estudos da área de Psicologia Organizacional foram tornando-se cada vez mais necessários. A grande demanda de atividades nessa área nos ambientes organizacionais privados apresentam atuação superior nos ambientes públicos, demostrando a necessidade de um olhar mais voltado ao servidor. Segundo Murillo e Moralles (2015), um indivíduo com Síndrome de Burnout provavelmente prestará serviços inadequados aos clientes, será inoperante em suas funções ou terá uma média de absenteísmo acima do normal, expondo a organização à perdas econômicas e falhas ao buscar atingir metas.

Nesse sentido, pode-se destacar, nessa reflexão, que a síndrome é considerada pela Organização Mundial da Saúde (OMS) como um risco ocupacional. É preciso auferir, também, que os recursos humanos na Administração Pública ainda se encontram pouco difundidos, restringindo o teor mais "humano" das organizações, acarretandose, dessa forma, o desprezo de emoções, sentimentos e das necessidades dos servidores. A importância da difusão desse ramo de conhecimento, apesar de ser ainda muito restrito, pode ser muito expressivo para o desenvolvimento de um serviço de melhor qualidade para a população, objetivo principal da Administração Pública, $e$, 
ainda, para que haja a consecução dos interesses coletivos, como afirma Pietro (1997).

\subsection{GESTÃO DE PESSOAS NA ADMINISTRAÇÃO PÚBLICA}

Historicamente, as políticas de gestão de pessoas na Administração Pública no Brasil tomaram forma na década de 1930, mais especificamente a partir da década de 1937. Os primeiros índices de uma atuação no campo da Psicologia Organizacional e de Gestão de Pessoas caracterizaram o primeiro grande esforço de inovação do sistema público do país, marcado por dificuldades significativas. O escopo principal, nesse momento histórico, acarretou a criação do Departamento Administrativo do Serviço Público (DASP), que, em suas funções administrativas, englobava as atribuições de um Departamento de Pessoal, com incumbências de ordem legal (OLIVEIRA; MEDEIROS, 2011). Essas tentativas de uma maior intervenção na dimensão de Gestão de Pessoas no ambiente organizacional mostrou-se expressiva, no entanto, é perceptível que o alcance da desse feito foi abreviado.

Nogueira (2005), afirma que os esforços foram concentrados basicamente nos processos de seleção, treinamento e remuneração, tornando a interversão no campo pessoal, um movimento de dimensão externa ao trabalho. No entanto, se considerada a temática abordada no presente estudo, é notório que o problema em questão não consegue ser alcançado por esse modelo de gestão, podendo gerar danos para o bom funcionamento da Administração Pública, assim como para a saúde do servidor. A importância de gerir os servidores públicos, reconhecendo a relevância das relações humanas como um mecanismo para prever possibilidades de inatividade, a avaliação das condições do ambiente de trabalho e as consequências geradas nas relações laborais ainda são considerados fatores irrelevantes à qualidade do serviço público prestado.

Porém, se a administração latu sensu [4] é toda a atividade destinada a organizar o desenvolvimento das atividades humanas, menosprezar a composição dessas realidades tornam os esforços para a implementação da Gestão de Pessoas no Setor Público um movimento imperfeito. Considerando esse contexto, o estudo de Limongi- 
França (2007) compreende que toda pessoa é composta por um complexo sócio psicossomático, isto é, tem potencialidades biológicas, psicológicas e sociais que respondem simultaneamente às condições de vida. Assim sendo, destaca-se que a caracterização do ser humano faz com que ele seja entendido como um ser biopsicossocial, concepção essa advinda da Medicina Psicossomática, e, de acordo com essa perspectiva, todas as potencialidades enumeradas são interdependentes, sendo caracterizadas da seguinte maneira:

A camada biológica refere-se às características físicas herdadas ou adquiridas ao nascer e durante toda a vida. Inclui metabolismo, resistências e vulnerabilidades dos órgãos ou sistemas. A camada psicológica refere-se aos processos afetivos, emocionais e de raciocínio, conscientes ou inconscientes, que formam a personalidade de cada pessoa e o seu modo de perceber e posicionar-se diante das pessoas e das circunstâncias que vivencia. A camada social incorpora os valores; as crenças; o papel na família, no trabalho e em todos os grupos e as comunidades a que cada pessoa pertence e de que participa. O meio ambiente e a localização geográfica também formam a dimensão social (LIMONGI-FRANÇA, 2007, s/p).

Tendo em vista a relevância da composição das potencialidades existentes no ser humano e a influência dessas camadas no bom êxito de qualquer atividade realizada por ele e que o estudo da Gestão de Pessoas deu-se por advento do homem social, pode-se inferir que a Visão Biopsicossocial encontra-se diretamente ligada ao desenvolvimento do servidor no ambiente laboral. Foi considerado de grande valia que o estudo fosse desenvolvido no Setor Público da Assistência Social do Município de Itaocara - RJ, principalmente por possuírem, como usuários, pessoas desprovidas dos mínimos sociais para a garantia do atendimento das necessidades básicas do ser humano com vistas a diagnosticar a possível influência desse trabalho nas vidas dos servidores e nas potencialidades identificadas pelo autor.

Por representar o setor público que atua diretamente com aqueles que necessitam de intervenção do Estado, como a própria Constituição Federal garante, entende-se, com 
esse estudo, que: "a assistência social será prestada a quem dela necessitar, independentemente de contribuição à seguridade social" (Art. 203), e, desse modo, torna-se válido reiterar que um dos motivos pelos quais a Síndrome de Burnout se desenvolva, e, ainda, em razão da ineficácia dessa política, compreende-se que a falta da assistência pode ocasionar grandes consequências nas vidas usuários devido as falhas do serviço prestado. Logo, é nesse cenário que o estudo explora o contexto do ambiente de trabalho, as consequências na vida pessoal e profissional dos servidores, geradas pelos conflitos vivenciados pelos usuários, os reflexos das condições presenciadas no ambiente de trabalho e a ação desses confrontos no que tange a saúde emocional desses profissionais oriunda da atuação nesse serviço público.

\subsection{CONTEXTO LABORAL DA ASSISTÊNCIA SOCIAL DO MUNICÍPIO}

Chiavenato (2004) assegura que para administrar as pessoas é preciso compreender seus comportamentos e o ambiente com o qual elas interagem. Dentro desse contexto, vale ressaltar as questões vivenciadas pelos servidores na política de Assistência Social, o ambiente laboral e os conflitos decorrentes deste trabalho, pois são determinantes para identificar a ação da síndrome aqui considerada nos profissionais desse setor. Como abordamos, um setor da administração pública municipal deve referenciar o contexto econômico e populacional, pois isso é de suma importância.

Assim sendo, tendo em vista que os mesmos dados são utilizados para o desenvolvimento de qualquer atividade pública, cabe alguns apontamentos. Mesmo não podendo ser caracterizada como um serviço de natureza universal, a Assistência Social possui sua estruturação no contexto que se apresenta inserida, buscando a garantia das necessidades locais. O município de Itaocara, localizado no estado do Rio de Janeiro, segundo o Censo do IBGE (2010), possui uma população estimada em 23.234 pessoas, e, desse modo, o contexto econômico do município apresenta os seguintes índices: 
Em 2017, o salário médio mensal era de 1.8 salários mínimos. A proporção de pessoas ocupadas em relação à população total era de 19.4\%. Na comparação com os outros municípios do estado, ocupava as posições 59 de 92 e 40 de 92, respectivamente. Já na comparação com cidades do país todo, ficava na posição 2999 de 5570 e 1406 de 5570, respectivamente. Considerando domicílios com rendimentos mensais de até meio salário mínimo por pessoa, tinha $33.4 \%$ da população nessas condições, o que o colocava na posição 65 de 92 dentre as cidades do estado e na posição 3928 de 5570 dentre as cidades do Brasil.

Segundo os dados da Secretaria da Assistência Social do município estudado, no fim do ano de 2019, o número de usuários assistidos era estimado entre 12 a 15 mil pessoas, sendo este número um rotativo constante, visto que esse grupo é formado por idosos, enfermos, pessoas em situação de rua, moradores da zona rural, entre outros. A equipe responsável por estes usuários encontrava-se composta por uma média de 50 servidores. É notório que apesar da condição econômica do município, ele não apresenta índices exorbitantes devido ao reduzido número de pessoas. Todavia, a quantidade de usuários assistidos em relação ao número de servidores é contraditória, visto que a maior parte dos servidores possuem funções distintas nesse contexto, por vezes podendo sobrecarregar determinado servidor, e, assim, devido à grande preocupação com questões de vulnerabilidade do assistido, pode ter a sua saúde emocional comprometida.

Considerando os mesmos dados, cabe destacar que o percentual de usuários se encontra entre $54 \%$ a $67 \%$ da população. É necessário, portanto, vislumbrar que a atuação na gestão social não se apoia apenas no indivíduo em si, mas, sobretudo, no contexto no qual esse sujeito encontra-se inserido. A eficácia da Gestão Social no contexto desse município é de suma importância, sendo determinante e responsável por mais da metade da população. A função da Assistência Social não é apenas assistencialista, há, também, o dever de promover a transformação social a partir das medidas previstas em lei, visando a garantia do mínimo de condições para uma 
existência digna. Nesse sentido, a Assistência Social busca integrar e incluir o assistido na sociedade e promove atividades que garantem a subsistência deste no contexto social. A LOAS confere, então, à Assistência Social, o status de política pública, sendo direito do cidadão e dever do Estado.

Definida pela Constituição Federal em seus Arts. 203 e 204 e pela Lei 8742/93, a Assistência Social é prestada aos cidadãos por meio do Sistema Único da Assistência Social (SUAS), composto por Centros de Referência da Assistência Social e Entidades da Assistência Social, dividindo-se em: Proteção Social Básica e Proteção Social Especial. A primeira vertente tem como escopo principal a garantia do fortalecimento do vínculo entre a esfera familiar e a comunidade. Volta-se, portanto, aos indivíduos e/ou grupos com comprovada situação de vulnerabilidade social, como, por exemplo, a pobreza, a privação (ausência de renda, pouco ou nenhum acesso aos serviços públicos etc) e/ou em razão de possuírem vínculos afetivos, relacionais e de pertença frágeis, como é o caso de indivíduos e/ou grupos alvos de discriminação por questões etárias, étnicas, raciais, de gênero, em razão de deficiências etc. É garantida pelo Sistema Único da Assistência Social e pelos Centros de Referência de Assistência Social - CRAS.

O Centro de Referência de Assistência Social - CRAS é uma unidade pública estatal descentralizada da política de assistência social sendo responsável pela organização e oferta dos serviços socioassistenciais da Proteção Social Básica do Sistema Único de Assistência Social (SUAS) nas áreas de vulnerabilidade e risco social dos municípios e DF (MINISTÉRIO DO DESENVOLVIMENTO SOCIAL E COMBATE À FOME, 2009, p. 9).

A Proteção Social Especial, por conseguinte, trata-se de uma vertente que se direciona à famílias e indivíduos que se encontram em situação de risco em razão de problemas como abandono, maus tratos físicos/psíquicos, abuso sexual, uso de substâncias psicoativas, cumprimento de medidas socioeducativas, situação de rua ou de trabalho infantil etc (POLÍTICA NACIONAL DE ASSISTÊNCIA, 2004). Destarte, tais problemas necessitam de um acompanhamento mais especializado, devendo, 
ainda, haver uma maior flexibilidade nas soluções protetivas, nos encaminhamentos monitorados, nos processos que visam a qualidade da atenção protetiva e para que haja uma efetiva reinserção desse indivíduo/família. O Centro de Referência Especializado de Assistência Social (CREAS) pode ser auferido como uma entidade pública do Estado, e, em razão disso, acompanha indivíduos e famílias que tiveram seus diretos violados ou que estão sob ameaça.

Souza (2013) afirma que as políticas sociais governamentais são um movimento multidirecional resultante do confronto de interesses contraditórios e, também, enquanto mecanismos de enfrentamento da questão social, são resultantes do agravamento da crise socioeconômica, das desigualdades sociais e da concentração de renda. A partir dessa dimensão torna-se cada vez mais visível que o ambiente de trabalho desses servidores é marcado pela pressão, pela desigualdade, pela violência doméstica, pela falta de perspectiva, pela extrema pobreza, pelo abuso sexual e moral, pela ausência planejamento familiar, enfim, interações altamente demandantes de esforço emocional. O mesmo autor caracteriza o trabalho como "cenário de (re)produção de diferentes emoções", dispondo, para tanto, acerca das situações vivenciadas, surgindo, então, questionamentos sobre a atual situação motivacional desses trabalhadores e os efeitos advindos das diferentes emoções vivenciadas no ambiente laboral.

Assim sendo, aufere-se que se meio e o comportamento interferem diretamente na administração das pessoas, como afirma Chiavenato (2013), a anulação das relações humanas e das emoções nesse contexto podem produzir grandes danos para a organização.

\subsection{TRABALHO X MOTIVAÇÃO}

$\mathrm{Na}$ Grécia Antiga, a motivação era vista, principalmente pelos filósofos que procuravam abordar e refletir sobre o tema, que essa precisava ser compreendida como uma força motor ou força interior produtora de uma determinada atitude. Todavia, a temática continua atual, podendo, também, ser compreendida como responsável pela intensidade, direção e persistência dos esforços de uma pessoa 
para o alcance de determinadas metas, com afirma Camargo (2009). O trabalho e a motivação podem ser consideradas vias que caminham unidas. $\mathrm{Na}$ vida moderna, o trabalho não se centraliza apenas em uma meta, um fim último. Porém, encontra-se inteiramente interligado com o reconhecimento do "ser". A professora, o médico, o administrador, enfim, a identificação da profissão torna-se determinante para a localização do indivíduo na sociedade.

Fato ratificado por Pines (1993), e, assim, afirma que o labor, atualmente, absorveu um novo sentido: compreende-se, então, que a vivência anterior, presente e futura de um sujeito toma forma para além do desempenho de tarefas cotidianas no contexto de trabalho. Logo, a ausência de motivação em um colaborador apresenta principalmente um rompimento do mesmo com suas expectativas e com sua identidade, possivelmente evoluindo para a despersonalização e escassez da auto realização, características consideradas como o mote para que a Síndrome de Burnout se manifeste. Nesse contexto, é notório que a atuação no ambiente de trabalho perpassa as emoções daquele que o exerce. Essa atitude além de interferir na produção de serviço para a organização, causa, no indivíduo, aumento nos índices de absenteísmo e dificuldades nas relações interpessoais no ambiente de trabalho.

Nesse sentido, Pines (1993), em seu estudo, alude que há a necessidade de identificar o possível desenvolvimento da síndrome, compreendendo-se, também, que ela não encontra-se fechada em si mesma, uma vez que a ausência de motivação pode ser "ponte" para ocasionar diversas mudanças no contexto organizacional, assim como no contexto pessoal. $O$ aumento da influência da gestão de pessoas nos setores administrativos privados são incontestáveis, tornando cada vez mais perceptível a importância do desenvolvimento da Psicologia Organizacional. No entanto, quando discutida no cenário público, sua execução encontra-se limitada pelo pouco investimento nessa área. Não se pode descartar as inúmeras relevâncias dos outros setores como Educação e Saúde, que apresentam necessidade de uma maior infraestrutura e investimento.

Porém, sendo a garantia do bem coletivo, a Administração Pública, no contexto atual, quando não faz uso de uma estrutura que percorra o meio individual e pessoal dos 
servidores, pode dificultar um melhor êxito da gestão. Fato evidenciado por Antunes (2000), visto que reitera que o trabalho está intimamente ligado com os aspectos que perpassam a vida pessoal, e, para ele, não associar a vida laboral com a vida pessoal é incompatível com uma vida significativa fora do contexto laboral. Antunes (2000), elucida que a motivação no âmbito do trabalho converte-se em uma vida dotada de sentido na esfera pessoal. Reafirma-se, então, a necessidade do indivíduo de encontrar realização e motivação na esfera do trabalho. Dados comprovam que os servidores públicos passam, em média, um terço do seu dia no ambiente de trabalho, significando que as emoções vivenciadas neste local interferem diretamente na vida do trabalhador.

Quando discutimos sobre o cenário do ambiente laboral no âmbito da Assistência Social, constata-se que há uma enorme carga de emoções experimentadas não apenas pelos servidores, mas, sobretudo, pelos usuários. No exercício dessas profissões, os profissionais envolvem-se em uma relação com o cliente, permeada de ambiguidades (BORGES; ARGOLO; PEREIRA, 2002). Ajudar as pessoas sempre foi visto pela sociedade como algo nobre e a empatia continua sendo imprescindível para entender, compreender e ajudar pessoas. No entanto, no decorrer dos anos, passouse a refletir sobre os aspectos emocionais provenientes dessas atividades. Como incita Barmejo (2012), para a existência da empatia há o uso de um "esforço pessoal". Entretanto, quando não é equilibrado, gera-se, no trabalhador, sentimentos de desmotivação e sintomas característicos da Síndrome de Burnout.

\subsection{SÍNDROME DE BURNOUT}

Nos estudos de Maslach e Jackson (1981) a Síndrome de Burnout foi conceituada como uma síndrome de exaustão emocional e cinismo que ocorre frequentemente entre indivíduos que realizam algum tipo de trabalho para outras pessoas. A palavra "burnout" pertence ao vocabulário inglês e remete àquilo que não funciona em razão da exaustão da energia. Nesse sentido, a terminologia aponta para o fato de que a síndrome representa os aspectos crônicos que causam estresse no contexto corporativo. O ambiente de trabalho é o fator determinante para o desenvolvimento da Síndrome, destacando que a efetividade de uma atividade não se encontra limitada 
apenas a área de conhecimento a qual atua, pelo contrário, o conhecimento puramente técnico é capaz de levar o servidor até um certo ponto.

Aponta-se, considerando o contexto apresentado que, após chegar a esse ponto máximo, as habilidades interpessoais tornam-se imprescindíveis" (ROBBINS, 2002). Assim sendo, cabe reiterar que os reflexos desse desgaste emocional se fazem visíveis nos sintomas que são muito característicos da doença. Desencadeado pelo estresse ocupacional, na tentativa de sobreviver as dificuldades, o corpo, em um primeiro momento, manifesta-se a partir de elementos característicos à uma sobrecarga, contudo, na incidência da situações vivenciadas no cotidiano, acarretase sintomas que se tornam crônicos. De acordo com Benevides-Pereira (2002), são divididos em sintomas físicos, de ordem psíquica, de ordem comportamental e defensivos. Sendo eles:

Os sintomas físicos compreendem a sensação de fadiga constante e progressiva, distúrbios do sono, dores musculares ou osteomusculares, cefaleias, enxaquecas, perturbações gastrointestinais, imunodeficiência, transtornos cardiovasculares, distúrbios do sistema respiratório, disfunções sexuais e alterações menstruais nas mulheres. Entre os sintomas psíquicos constata-se a falta de atenção e de concentração, alterações da memória, lentificação do pensamento, sentimento de alienação, de solidão, de insuficiência, impaciência, desânimo, disforia, depressão, desconfiança e paranoia. Já os sintomas comportamentais compreenderiam a falta ou excesso de escrúpulos, irritabilidade, incremento da agressividade, incapacidade para relaxar, dificuldade de aceitação de mudanças, perda de iniciativa, aumento do consumo de substâncias, comportamento de alto risco e aumento da probabilidade de suicídio. Os sintomas defensivos caracterizam-se pela tendência ao isolamento, sentimento de onipotência, perda do interesse pelo trabalho ou pelo lazer, insônia e cinismo. Para Varoli (2002), todas as questões referentes aos sintomas são mal elaboradas, pois, equivocadamente se deposita nas pessoas que se encontram desgastadas um problemas que 
nelas apenas é revelado, pois tem origem no desequilíbrio entre o trabalhador e o trabalho. Moreno e Oliver (1993) afirmam que os mais afetados por esta síndrome são, sobretudo, os profissionais mais iludidos, os mais esperançosos, aqueles cujas expectativas são mais altas, e, às quais a realidade

vem restringir, vem frustrar. Assim, como consequência, o profissional acaba por substituir uma atitude de dedicação e compromisso, de crença em si mesmo, por uma atitude apática e desinteressada. Também Freudenberger (1974) alude ao fato de serem justamente os profissionais mais dedicados e mais comprometidos com o trabalho os mais propensos a desenvolver Burnout (BENEVIDES-PEREIRA, 2002 apud MALLAR; CAPITÃO, 2004, p. 20).

Maslach (1978) e de Freudenberger (1974), em seus estudos, dispuseram sobre a identificação de características que auxiliam na identificação do possível desenvolvimento da síndrome. Afirmam que o conceito empregado para se referir à Síndrome de Burnout toma forma a partir de um conjunto que possui três variáveis ou dimensões essenciais que especificam e demarcam tal fenômeno, sendo elas: a exaustão emocional (EE), a despersonalização (D) e a diminuição da realização pessoal (DRP). Apontam que apesar de apresentar sintomas físicos, os sintomas emocionais e psíquicos são determinantes para o diagnóstico da Síndrome de Burnout, comorbidade que pode ocasionar até a inatividade do servidor. Tendo em vista as diversas situações vivenciadas por um servidor da Assistência Social do município de Itaocara-RJ, o presente estudo buscou avaliar a partir de variáveis demográficas, laborais e psicossociais a possível presença da Síndrome de Burnout.

\section{PROCEDIMENTOS METODOLÓGICOS}

\subsection{POPULAÇÃO}

O estudo teve como amostra 50 profissionais que atuam na Secretária de Assistência Social do município de Itaocara, localizado no interior do estado do Rio de Janeiro. 
Pertencem à diversas realidades e à diferentes áreas do conhecimento que variam de acordo com o ramo de graduação e com a atividade realizada no contexto ocupacional. A amostra contempla o grupo estudado, assistentes sociais, psicólogas, sociólogos, gestores, técnicos, advogados, dentre outros.

\subsection{INSTRUMENTO}

Aplicou-se a um questionário voltado à identificação preliminar da Síndrome de Burnout com o objetivo de detectar a finalidade do estudo, elaborado e adaptado por Chadfic Jbeilli e inspirado no inventário de Burnout de Maslach- IBM. Conforme Silva e Carlotto (2003), a versão da ferramenta traduzida, adaptada e validada no contexto brasileiro foi fomentada pelo estudo de Benevides-Pereira (2002). Trata-se de um inventário auto aplicado que tem como escopo analisar como o sujeito se relaciona com o trabalho a partir de três dimensões: exaustão emocional ( 3 itens), realização profissional ( 3 itens) e despersonalização (3 itens), obtendo-se um total de 9 itens.

A partir desse modelo empregado, em razão da necessidade de se avaliar os membros componentes da amostra, adotou-se um sistema de pontuação. A sua escala varia de uma cinco pontos. Ao ser adaptado para o contexto brasileiro, verificou-se que os indivíduos envolvidos apresentavam certas dificuldades no que tangia à dificuldade para se responder muitos itens, o que invalidava esse modelo. Assim sendo, os critérios da escala original foram adaptados. Nesse sentido, alguns apontamentos se fazem necessários. O número um indica "nunca", o número 2 para "algumas vezes ao ano", o número três para "algumas vezes ao mês, o número quatro para "algumas vezes na semana" e cinco para diariamente.

\subsection{PROCEDIMENTO}

Primeiramente, foi realizado um contato com a direção da Secretaria Municipal de Assistência Social para apresentar o objetivo do estudo a fim de obter a autorização e o apoio para a aplicação do instrumento. Após o consentimento e o acolhimento do estudo por parte dos servidores, foi aplicado o questionário cujo propósito foi levantar as variáveis demográficas, profissionais e laborais, seguido do Maslach Burnout 
Inventory (MBI). Todavia, vale ressaltar que o questionário não substitui o diagnóstico de um profissional da área, sendo utilizado apenas para uso informativo.

\subsection{RESULTADOS}

O Banco de dados foi levado para o Microsoft Office Excel 2013, para o apurar os resultados. E através da análise dos dados recolhidos pelo questionário, verificou-se através da moda estatística de cada resposta, caracterizando de maneira global, em média 16 pontos na escala analisada. De acordo, com a descrição apresentada pelo modelo de Malasch recomenda-se cuidados de prevenção para a Síndrome de Burnout, pois os profissionais apresentam características propicias para o desenvolvimento da doença psicossomática. Quando avaliados os níveis de esgotamento emocional, obtemos os seguintes dados:

Figura 1: Graduação do nível de exauste emocional dos servidores da Assistência Social

\section{Identificação Preliminar de Síndrome de Burnout Secretaria de Assistência Social, Itaocara-RJ \\ (Níveis de Esgotamento)}

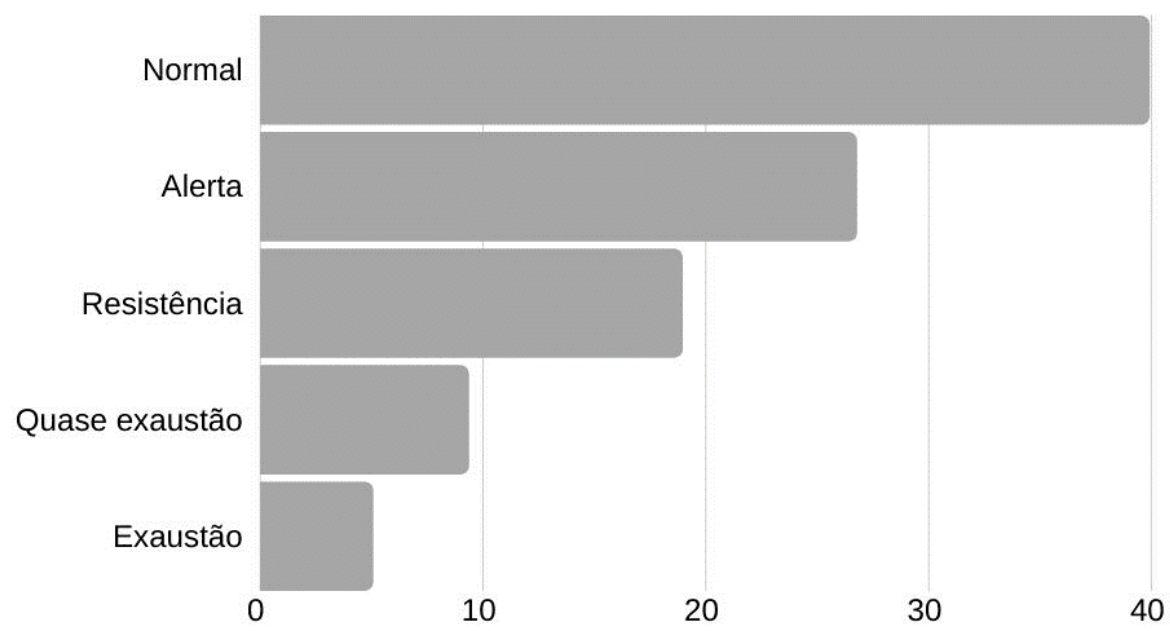

Fonte: Elaborada pela autora (2020) 
Figura 2: Indíces determinante para o desenvolvimento da Síndrome de Burnout, segundo Malasch (1986)

\section{Identificação Preliminar de Síndrome de Burnout Secretaria de Assistência Social, Itaocara-RJ (Modelo Maslach)}

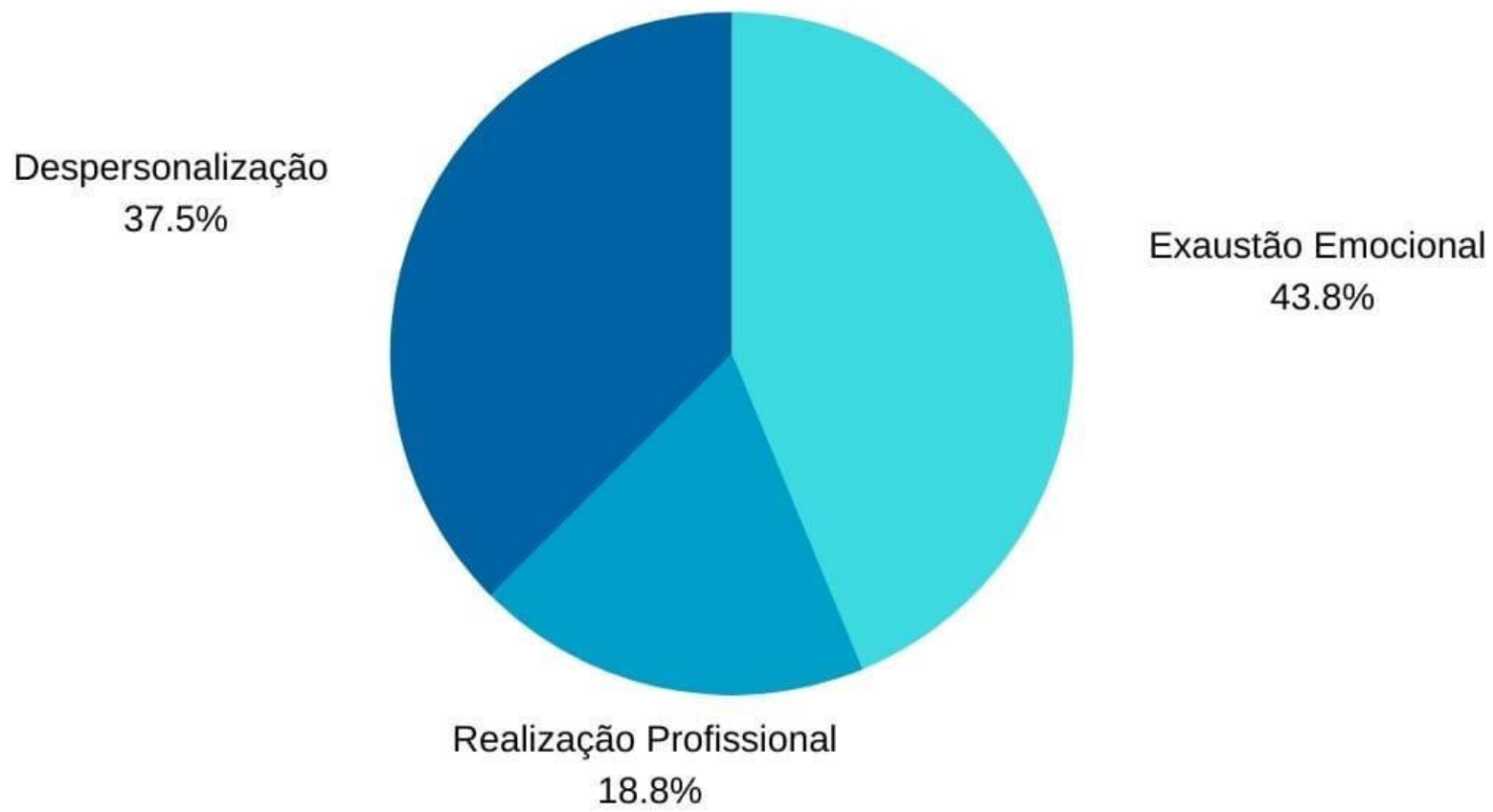

Fonte: Elaborado pela autora (2020)

Destarte, com as dimensões determinadas pelo autor, é possível perceber que apesar da pesquisa demostrar que a equipe possui uma propensão para o desenvolvimento da Síndrome de Burnout, cerca de $40 \%$ das respostas recolhidas determinam que os servidores não apresentam sinais de esgotamento e fadiga e perda de motivação, sintomas característicos da doença psicossomática aqui abordada. Fica evidente que cerca de $60 \%$ dos profissionais da área estudada manifestam sinais significativos do aumento de uma insuficiência emocional e apontam que há alterações em suas vidas pessoais em razão da influência do labor em seu cotidiano como um todo. Ao mesmo tempo, como aborda a imagem 2 (dois), a dimensão que apresenta menor índice de insatisfação é a de Realização Profissional, apresentando apenas 18,8\% identificando 
que o fator determinante para o não progresso da Síndrome de Burnout pelos servidores se deve ao sentimento de poder ajudar outras pessoas.

\section{DESENVOLVIMENTO}

A partir da pesquisa de campo foi possível perceber que devido a importância das relações interpessoais na atuação do contexto da assistência prestada aos cidadãos, os servidores têm apresentado um índice de estresse emocional fora da normalidade, advindo das atividades laborais. De acordo com Malasch (1986), a identificação do índice de exaustão emocional como o mais elevado (como demostrado na figura 2), aponta que a significativa carga emocional recebida por esses trabalhadores não tem permanecido apenas no ambiente de trabalho, tendo, também, influenciado no comportamento pessoal do servidor. A exaustão emocional é caracterizada pelo esgotamento dos recursos emocionais do indivíduo. É considerada o traço inicial da síndrome e decorre principalmente da sobrecarga e de situações conflituosas que se manifestam nas relações interpessoais (TUCUNDUVA; GARCIA; PRUDENTE, 2006).

O sentimento de levar consigo toda essa "bagagem" traz, ao trabalhador, uma alteração expressiva em suas dimensões psicológicas e emocionais. Logo, percebese que essa elevação de exauste emocional, além de ser muito alarmante para a saúde do servidor por apresentar uma condição precípua para o aparecimento da síndrome, no contexto organizacional também desdobra-se na dificuldade de estabelecer relações interpessoais, ação contraditória ao objetivo das atividades da Gestão Social. Já o elevado índice de despersonalização pode ser visto como um "risco" para o estabelecimento de eficácia das ações da Assistência Social, sendo conceituada como a ausência da sensibilidade, o que torna as pessoas mais frias quando respondem aos sujeitos relacionados ao serviço. Trata-se os clientes como meros objetos e não como os seres humanos que são.

Os funcionários, assim sendo, podem desenvolver sentimentos negativos, que, por sua vez, são repercutidos na forma de ações igualmente negativas. Nesse sentido, passam a culpabilizar os clientes pelos seus problemas e aflições, como elencam Maslach e Jackson, (1981). O excesso de envolvimento com as questões torna-se 
prejudicial para a saúde. No entanto, a ausência de empatia e a "desumanização" do processo é um desastre em meio as políticas sociais. Contudo, a realização profissional pode ser vista como um determinante para o servidor pesquisado, afinal, comparada aos outros índices, a realização encontra-se mais estável, promovendo, ao trabalhador, a compreensão da importância do seu trabalho e a influência deste para os seus usuários, que, no município de Itaocara-RJ, ultrapassa a metade da população, sendo um serviço de grande importância para a Gestão Municipal.

\section{CONSIDERAÇÕES FINAIS}

O artigo verificou a importância do estudos no campo da Gestão de Pessoas e Psicologia Organizacional, pois esse ramo possui pouca repercussão na esfera da Administração Pública, contudo, é relevante quando se deseja refletir sobre a qualidade da gestão e prestação de serviços ao público. Como relatado, o desenvolvimento da Gestão de Pessoas na Administração Pública do Brasil faz com que essa área seja ainda nova, e, assim, o conhecimento e prática por parte dos órgão públicos, mesmo após décadas de sua implantação, ainda se encontram em construção. Verificar o contexto laboral de um determinado setor da Administração Pública, não considerando apenas os resultados numéricos, traz uma perspectiva mais ampla, tornando esses gerenciamento eficiente, e, sobretudo, eficaz. Também é preciso levar em consideração que comparada à Gestão de Pessoas, estudos que enfatizam as realidades vivenciadas no contexto da prestação de serviços no setor da Assistência Social ainda são escassos.

Podem, portanto, ser mais expandidos, tendo em vista a complexibilidade de atuação e a diversidade de serviços prestados por parte das secretarias no âmbito municipal. Este artigo evidenciou, a partir das reflexões aqui elencadas, que a Síndrome de Burnout pode ser um fator de risco para o desempenho dos servidores da Assistência Social devido ao índice de esgotamento emocional por parte destes, apresentando dados que salientaram a necessidade de observar os sintomas da doença. E, por conseguinte, o estudo vislumbrou que mesmo em meio ao estresse do ambiente de trabalho, devido a empatia e a conjuntura de ajudar pessoas que necessitam, o grau de realização profissional desses servidores é um fator considerável, visto que permite 
a autorrealização destes. Do mesmo modo, cabe ressaltar que a falta de motivação é, então, um fator que pode desencadear inatividade e uma maior ocorrência dos casos da Síndrome de Burnout.

\section{REFERÊNCIAS}

BRUNA, M. H. V. Síndrome de burnout (esgotamento profissional). Disponível em: https://drauziovarella.uol.com.br/doencas-e-sintomas/sindrome-de-burnoutesgotamento-profissional/. Acesso em: 30 de ago. 2019.

CASTRO, F. G. de.; ZANELLI, J. C. Síndrome de burnout e projeto de ser. Cadernos de Psicologia Social do Trabalho, v. 10, n. 2, p. 17-33, 2007.

DUARTE, R. Pesquisa qualitativa: reflexões sobre o trabalho de campo. Cadernos de pesquisa, n. 115, p. 139-154, 2002.

ESCULÁPIO, M. A gestão de recursos humanos no serviço público. 2013. 34f. Monografia (Pós-graduação em Gestão Pública Municipal) - Universidade Tecnológica Federal do Paraná, Curitiba, 2013.

FIUZA, G. D. Políticas de gestão de pessoas, valores pessoais e justiça organizacional. RAM - Revista de Administração Mackenzie, v. 11, n. 5, p. 55-81, 2010.

HORTA, P.; DEMO, G.; ROURE, P. Políticas de gestão de pessoas, confiança e bemestar: estudo em uma multinacional. Revista de Administração Contemporânea, v. 16, n. 4, p. 566-585, 2012.

KOVALESKI, D. F.; BRESSAN, A. A síndrome de Burnout em profissionais de saúde. Saúde \& Transformação Social/Health \& Social Change, v. 3, n. 2, p. 107-113, 2012. 
Ministério do Desenvolvimento Social e Combate à Fome. Orientações Técnicas de Referência da Assistência Social - CRAS. Brasília: Ministério do Desenvolvimento Social e Combate à Fome, 2009.

MOTA, C. M.; DOSEA, G. S.; NUNES, P. S. Avaliação da presença da Síndrome de Burnout em Agentes Comunitários de Saúde no município de Aracaju, Sergipe, Brasil. Ciência \& Saúde Coletiva, v. 19, p. 4719-4726, 2014.

NEVES, D. R. et al. Sentido e significado do trabalho: uma análise dos artigos publicados em periódicos associados à Scientific Periodicals Electronic Library. Cadernos EBAPE, v. 16, n. 2, p. 318-330, 2018.

NOGUEIRA, A. J. F. M. Relações de trabalho no setor público. In: Ciclo de Debates em Economia Industrial, Trabalho e Tecnologia, 2005.

OLIVEIRA, J. A. de.; MEDEIROS, M. da. P. M. de. Gestão de pessoas no setor público. $2^{\mathrm{a}}$ ed. Florianópolis : Departamento de Ciências da Administração/UFSC; Brasília: CAPES: UAB, 2016.

PEDRO, W. J. A. Gestão de Pessoas. Revista Uniara, n.17/18, p. 1-3, 2005/2006.

PÊGO, F. P. L.; PÊGO, D. R. Síndrome de burnout. Rev. bras. med. trab, v. 14, n. 2 , p. 171-176, 2016.

PIETRO, M. Z. Z. Direito Administrativo. 8ㅡ ed. São Paulo: Atlas, 1997.

PIRES, D. A. et al. A síndrome de burnout no esporte brasileiro. Revista da Educação Física/UEM, v. 23, n. 1, p. 131-139, 2012.

RODRIGUES, A. P. G.; GONDIM, S. G. Expressão e regulação emocional no contexto de trabalho: um estudo com servidores públicos. RAM - Revista de Administração Mackenzie, v. 15, n. 2, p. 38-65, 2014.

SABORÍO MORALES, L.; HIDALGO MURILLO, L. F. Síndrome de Burnout. Medicina Legal de Costa Rica, v. 32, n. 1, p. 119-124, 2015. 
SALLES TEIXEIRA, M. C. de.; FRANÇA, S. L. B. Clima Organizacional e Satisfação no Trabalho: Contribuições para a Gestão Estratégica de Pessoas em Instituição Pública. In: Gestão e tecnologia para a competitividade, 2013.

SOUSA, M. M. F. de. S. et al. A Assistência Social como política pública de direito: avanços e desafios na efetivação dos direitos sociais. In: VI Jornada Internacional de Políticas Públicas, 2013.

\section{APÊNDICE - REFERÊNCIA DE NOTA DE RODAPÉ}

4. Lato sensu é uma expressão em latim que significa "em sentido amplo".

Enviado: Maio, 2020.

Aprovado: Junho, 2020. 